\title{
INFLUÊNCIA DA CURETAGEM ALVEOLAR NA CICATRIZAÇÃO APÓS EXODONTIA EM CÃES
}

Aron L. Katz ${ }^{*}$

KATZ, Aron L. - Influência da curetagem alveolar na cicatrização após exodontia em cães. Revista da Faculdade de Odontologia, Porto Alegre, 25:39-53, 1983.

Descritores: Curetagem - Alvéolo-dentária - Exodontia - Alvéolo seco.

\section{RESUMO}

Observação e comparação do padrão da cicatrização alveolar em cães, e sua repercussão nas estruturas adjacentes do canal e nervo dentário inferior, após extração dos terceiros molares mandibulares com subseqüente curetagem dos alvéolos direitos. Foi observada a deposição de neoformação óssea nas paredes superior e laterais do canal mandibular, circunscrevendo o respectivo nervo e provocando a sua constricção.

\section{INTRODUÇÃO E REVISÃO DA LITERATURA}

Um dos problemas mais freqüentes e controvertidos com que se depara o cirurgião-dentista que realiza exodontia, é a oportunidade ou não da curetagem alveolar após a extração dentária $(1,11$, $12,16,17,18)$.

Por um lado, reconhecemos como um dos requisitos gerais da extração dentária, que o traumatismo deve ser o mínimo indispensável, com a finalidade de obter um melhor pós-operatório; por outro lado, recomenda-se que a extração deve ser completada pela remoção de tecidos patológicos e que, ao extrair dentes portadores de "processos sépticos tranqüilos", impõe-se a curetagem alveolar para assegurar melhor cicatrização $(11,12)$.

Afirma-se categoricamente acerca da necessidade de proceder à eliminação dos tecidos patológicos periapicais mediante curetagem, ao mesmo tempo em que se reconhece ser mecanicamente impossível eliminar todo este tecido patológico $(11,12)$.

Entretanto, é preciso questionar a própria remoçãó sistemática, por meio da curetagem, de um tecido que não deve ser encarado como "o processo séptico" mas, antes, como uma reação inflamatória defensiva do organismo contra "o processo séptico" residente, em verdade, no conduto radicular. Ademais, um tecido de granulação semelhante ao

* Professor de Patologia Geral e de Patologia Buco-Dental do Departamento de Odontologia Conservadora 
curetado deverá ser elaborado durante o processo de cicatrização alveolar, levantando-se a questão acerca da oportunidade de pretender remover um tecido que, a seguir, será reconstituído como conseqüência da organização do coágulo no alvéolo dentário.

A curetagem, em tais casos, serviria mais para fragmentar e perturbar o tecido de granulação residual, sem mesmo assegurar a sua eliminação.

Restariam, assim, as alternativas de "ou fazermos uma curetagem que será sempre insuficiente, ou então não fazermos nenhuma curetagem com a finalidade de eliminar o tecido de granulação, ficando, em ambos os casos, atribuído à natureza a neutralização do foco" (11, 12). Tal orientação é interpretada de forma contraditória ao afirmar que "ante o dilema de proceder-se a uma limpeza imperfeita ou não fazê-la, devemos optar por fazê-la o melhor possível" $(5,11,12)$.

Mesmo atualmente continua sendo opinião dos mais abalizados autores que, “impondo-se a extração, e uma vez removido o dente responsável, o tecido inflamatório periapical, tanto o cisto como o granuloma, deveriam ser cuidadosamente curetados" $(11,21)$.

As relações de proximidade do conduto dentário inferior com o terceiro molar inferior, constituem motivo para atribuir as lesões dos nervos a fatores mecânicos de esmagamento e/ou estiramento por ocasião da extração destes dentes $(17,18)$. Entretanto, não devemos desprezar a possibilidade de que a propagação do processo inflamatório, desde o alvéolo traumatizado pela extração até a região do canal mandibular, via tecido medular, possa igualmente lesionar o nervo $(13,14,17,18)$.

\section{MATERIAL E MÉTODOS}

Foram feitas extrações dos terceiros molares mandibulares, esquerdo e direito, em cães. Os alvéolos direitos foram curetados com a finalidade de remover os restos do ligamento periodontal aderentes ao osso alveolar, ao passo que o outro alvéolo não foi curetado após a exodontia, servindo como controle comparativo no mesmo animal.

Os alvéolos foram examinados nos animais sacrificados após períodos variáveis de tempo, com a finalidade de estabelecer um quadro comparativo da velocidade e qualidade de cicatrização alveolar e estruturas anexas, inclusive na freqüência comparativa da instalação da osteíte alveolar (alveolitis sicca dolorosa).

Guardadas as diferenças de espécie, as conclusões das observações finais poderiam ser sugestivas no sentido de que, no homem, a sistemática curetagem alveolar após exodontia poderia ser benéfica, indiferente ou prejudicial para a cicatrização alveolar e repercução nas estruturas anexas, ao adicionar um traumatismo, possivelmente desnecessário, ao traumatismo da própria extração dentária.

Após a extração de 48 terceiros molares mandibulares em 24 cães, os animais foram sacrificados em pequenos grupos, transcorridos diversos períodos de tempo após o ato cirúrgico(1, 2, 4, 7, 14, 21 e 28 dias). As mandíbulas foram dissecadas e fotografadas. De cada mandíbula, após fixação, foram removidas, por corte vestíbulo-lingual, duas peças para processamento laboratorial. Cortes histológicos seriados e semi-seriados foram avaliados e os mais representativos 
foram microfotografados. As observações não se ativeram aos alvéolos curetados e não-curetados, mas se estenderam aos cortes transversais integrais das mandíbulas, visando fazer observações das repercussões à distância do local das extrações.

\section{RESULTADOS E DISCUSSÃO}

Por dificuldades de técnica laboratorial somente puderam ser avaliadas 36 das 48 peças originariamente obtidas para processamento.
Os resultados da seqüência, no tempo, do processo de cicatrização alveolar não variaram daqueles obtidos por outros autores $(1,2,3,4,6,7,8,9,10,15,19$, $20,22,23)$.

Será aqui enfocada a constatação que mereceu especial destaque, qual seja, a observação de neoformação óssea (osteófitos), reduzindo o diâmetro do canal mandibular, como repercussão em estruturas distantes da região de extração de terceiros molares mandibulares.

Quadro geral dos casos que apresentaram osteoplasia no canal mandibular.

\begin{tabular}{|c|c|c|c|c|}
\hline Fig. 1 & Cão nọ 7 & Peça 13 & Corte 16 & 7 dias pós-extração com curètagem \\
\hline Fig. 2 & Cão n? 7 & Peça 13 & Corte 16 & 7 dias pósextração com curetagem \\
\hline Fig. 3 & Cão n! 7 & Peça 14 & Corte 14 & 7 dias pós-extração sem curetagem \\
\hline Fig. 4 & Cão n? 12 & Peça 23 & Corte 1 & 7 dias pós-extração com curetagem \\
\hline Fig. 5 & Cão n? 17 & Peça 33 & Corte 9 & 21 dias pós-extração com curetagem \\
\hline Fig. 6 & Cão n! 17 & Peça 33 & Corte 9 & 21 dias pós-extração com curetagem \\
\hline Fig. 7 & Cão n? 18 & Peça 36 & Corte 6 & 21 dias pós-extração sem curetagem \\
\hline Fig. 8 & Cão n! 20 & Peça 39 & Corte 18 & 28 dias pós-extração com curetagem \\
\hline Fig. 9 & Cão n! 23 & Peça 45 & Corte 30 & 28 dias pós-extração com curetagem \\
\hline Fig. 10 & Cão n! 23 & Peça 45 & Corte 30 & 28 dias pós-extração com curetagem \\
\hline
\end{tabular}

Houve neoformação óssea em 5 casos de alvéolos que tinham sido curetados e em 2 não curetados.

A primeira indicação de neoformação óssea no canal mandibular foi observada aos 7 dias após a extração, sendo 2 casos em dentes com curetagem (Figs. 1,2 e 4) e 1 caso em dente sem curetagem após a extração (Fig. 3).

Aos 21 dias após a extração, foi constatada a presença de osteófitos na porção superior do canal mandibular, em 1 caso com curetagem e em 1 caso sem curetagem, notando-se a simultaneidade e simetria das neoformações ósseas no alvéolo e na porção superior do canal mandibular, conforme figuras 5, 6 e 7 .

Decorridos 28 dias após a extração, foi observada uma acentuada neoformação óssea no canal mandibular acima e dos lados do nervo (Fig. 8) circunscrevendo o nervo e tendendo à sua contricção, assim como nas figuras 9 e 10.

$\mathrm{O}$ aspecto de envolvimento e constricção do nervo é compatível com a possibilidade de provocação dolorosa e/ou parestesia, durante um período variável de tempo, conforme o grau de compressão do nervo e persistência da neoformação óssea.

R. Fac. Odont. P.A. 


\section{CONCLUSÕES}

19) Houve formação óssea simultânea no alvéolo e no canal mandibular, em alguns casos de extração de terceiros molares mandibulares em cães.

29) Houve formação óssea simultânea no alvéolo e no canal mandibular, em maior número de çasos, quando as extrações dos terceiros molares mandibulares em cães foram seguidas de curetagem alveolar.

39) 0 padrão topográfico da neoformação óssea no canal mandibular, envolvendo e comprimindo o nervo, sugere a possibilidade de uma participação etiológica entre os fatores que podem ocasionar dor ou parestesia após exodontias.

\section{SYNOPSIS}

Effects of curettage on the healing pattern of extraction wounds and their surrounding structures of the mandibular canal and merve were observed and compared after extraction of mandibular third molars from dogs, the right alveoli having been submitted to a thorough curettage. New bone deposition on the upper and lateral walls of the mandibular canal was observed, surrounding and squeezing the nerve.

\section{REFERÊNCIAS BIBLIOGRÁFICAS}

1. ALLING, C.C. \& KERR, D.A. - Trauma as a factor causing delayed repair of dental extraction sites. J. Oral Surg., 15(1):3-11, Jan. 1957.

2. AMLER, M.H. et alii - Histological and histochemical investigation of human alveolar socket healing in undisturbed extraction wounds. J. Am. Dent. Assoc., 61(1):32-44, July, 1960. 
3. AMLER, M.H. - The time sequence of tissue regeneration in human extraction wounds. Oral Surg., 27(3):309-18, Mar. 1967.

4. AMLER, M.H. - Pathogenesis of disturbed extraction wounds. J. Oral Surg., $31(9): 666-74$, Sept. 1973.

5. BÉKY, Josef - Sobre el cuidado del alvéolo despues de la extracción. $Z$. $R$. (9) 1941, apud, Rev. Asoc. Odontol. Argent., 29(11):715, Nov. 1941. Traducción e condensación de $E$. Gietz.

6. BOYNE, P.J. - Osseous repair of postextraction alveolus in man. Oral Surg., $21(6): 805-13$, June 1966.

7. CHAHÉR, J. et alii - Alterações epiteliais após extração parcial de dentes no rato. R. Fac. Odont. P.A., 3: 107-11, 1961.

8. CLAFLIN, R.S. - Healing of disturbed and undisturbed extraction wounds. J. Am. Dent. Assoc., 23(6):945-59, June 1936.

9. COMMISSIONAT, Y. - Quelques considerations sur la pathogénie des alvéolites. Actual. Odontostomatol., 18:203-20, 1964.

10. ELWELL, K.R. - A new approach to the treatment of dry socket. J. Am. Dent. Assoc., $31(5): 615-21$, May 1944.

11. GIETZ, E. et alii - Seccion consultas: oportunidad de curetar el alvéolo después de las extracciones. Rev. Asoc. Odontol. Argent., 30(5):265-8, May 1942.

12. GIETZ, E. - Cirugía oral menor. Buenos Aires, Progrental, 1946.

13. HUEBSCH, R.F. et alii - The healing process following molar extraction. I. Normal male rats (Long-Evans Strain). Oral Surg., 5(8):864-76, Aug. 1952.

14. HUEBSCH, R.F. -- Clinical and histological study of alveolar osteitis. J. Oral Surg., 16(11):473-82, Nov. 1958.

15. JOHANSEN, J.R. - Repair of the post-extraction alveolus in the Wistar rat. A histologic and autoradiographic study. Acta Odontol. Scand., 28(4):440-61, Aug. 1970.

16. ORLEAN, S.L. - Postoperative pain and its control by the general practitioner. Dent. Cosmos, 78:743-9, July 1936.

17. RIES CENTENO, G.A. - Las relaciones del conducto dentario inferior con el tercer molar. Rev. Asoc. Odontol. Argent., 45:246, 1947.

18. RIES CENTENO, G.A. - Cirugía hucal. Buenos Aires, El Ateneo, 1979.

19. SCHIFINO, L. - Alveolite e seu tratamento. Rev. Gaúcha Odontol., 3(2):64-9, abr./jun. 1955.

20. SCHRAM, W.R. - A histologic study of repair in the maxillary bones following surgery. J. Am. Dent. Assoc., 16:1987-97, Nov. 1929.

21. SHAFER, W.G. et alii - Patologia bucal. Trad. e adapt. da 3.ed. original. Rio de Janeiro, Interamericana, 1979.

22. SIMPSON, H.E. - The healing of extraction wounds. Br. Dent. J., 126:550-7, June 1969.

23. SIMPSON, H.E. - Experimental investigation into the healing of extraction wounds in macacus rhesus monkeys. J. Oral Surg., 18(5):391-9, Sept. 1960.

R. Fac. Odont. P.A. 


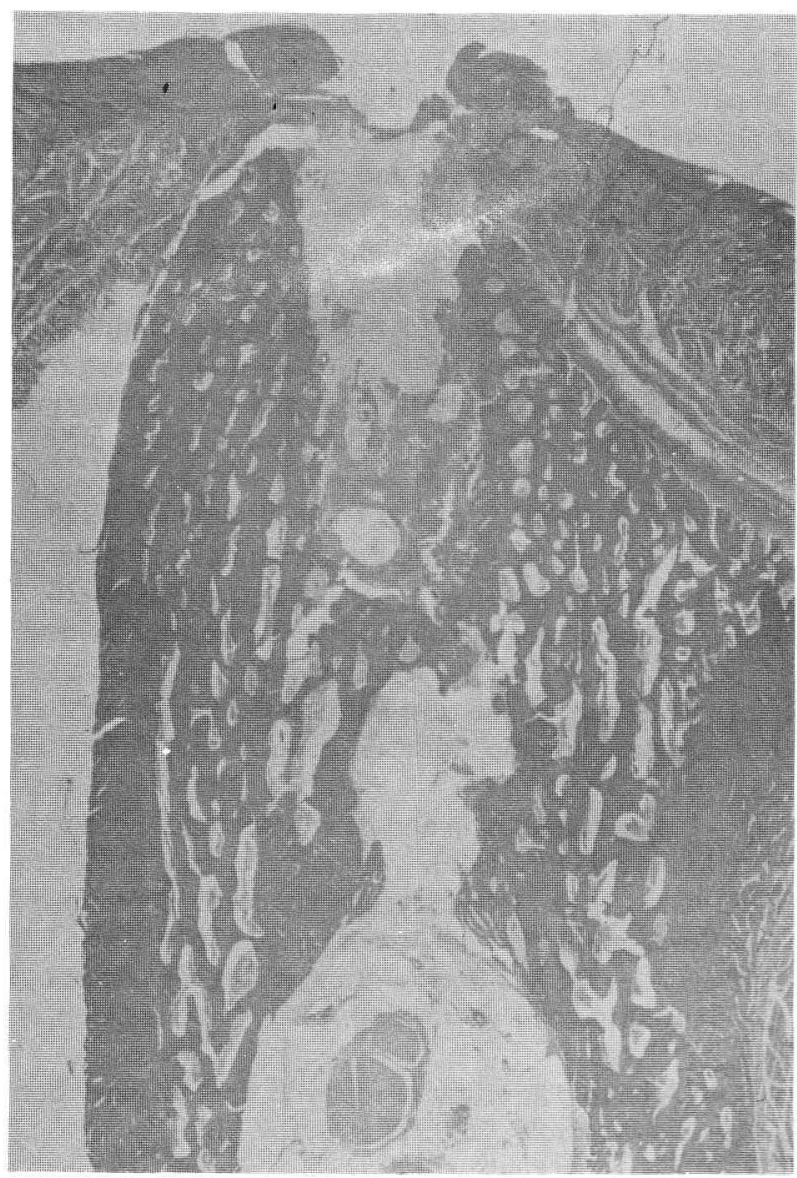

Fig. 1 Cão n! 7 Peça 13 Corte 16

7 dias pós-extração com curetagem

R. Fac. Odont. P.A. 


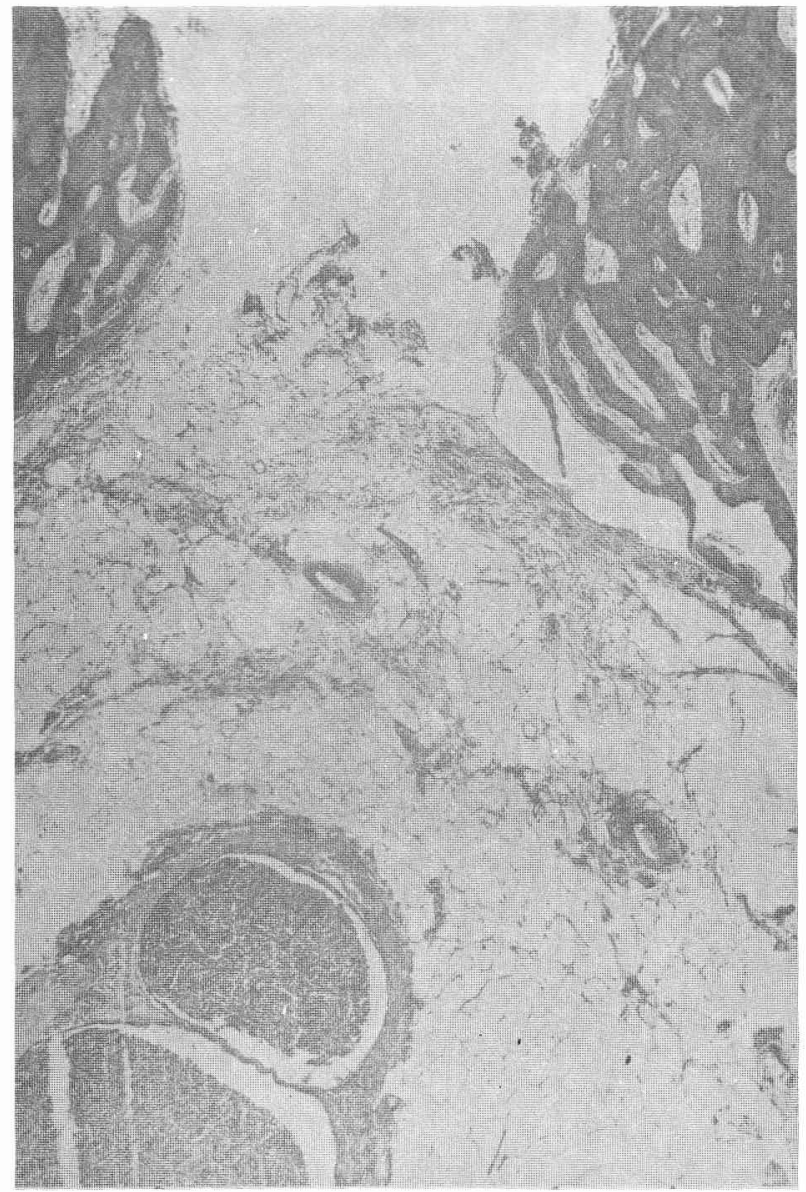

Fig. 2 Cão no 7 Peça 13 Corte 16 7 dias pós-extração com curetagem 


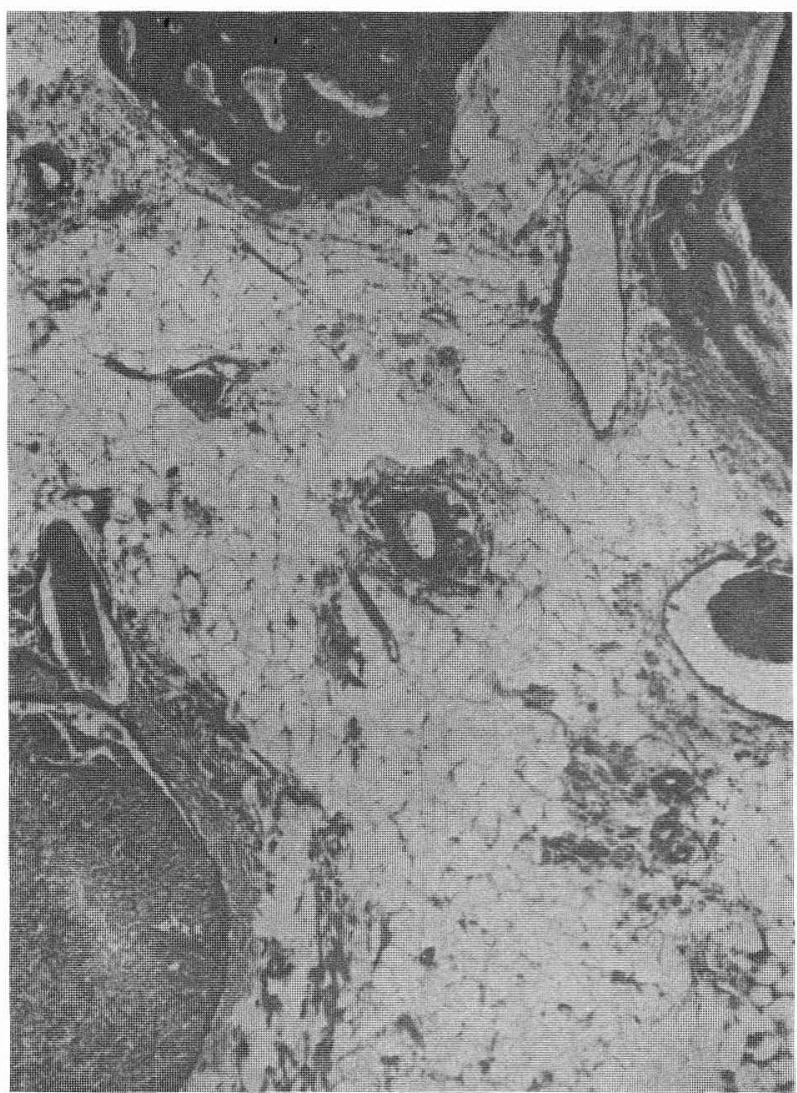

Fig. 3 Cão n? 7 Peça 14 Corte 14 7 dias pós-extração sem curetagem 


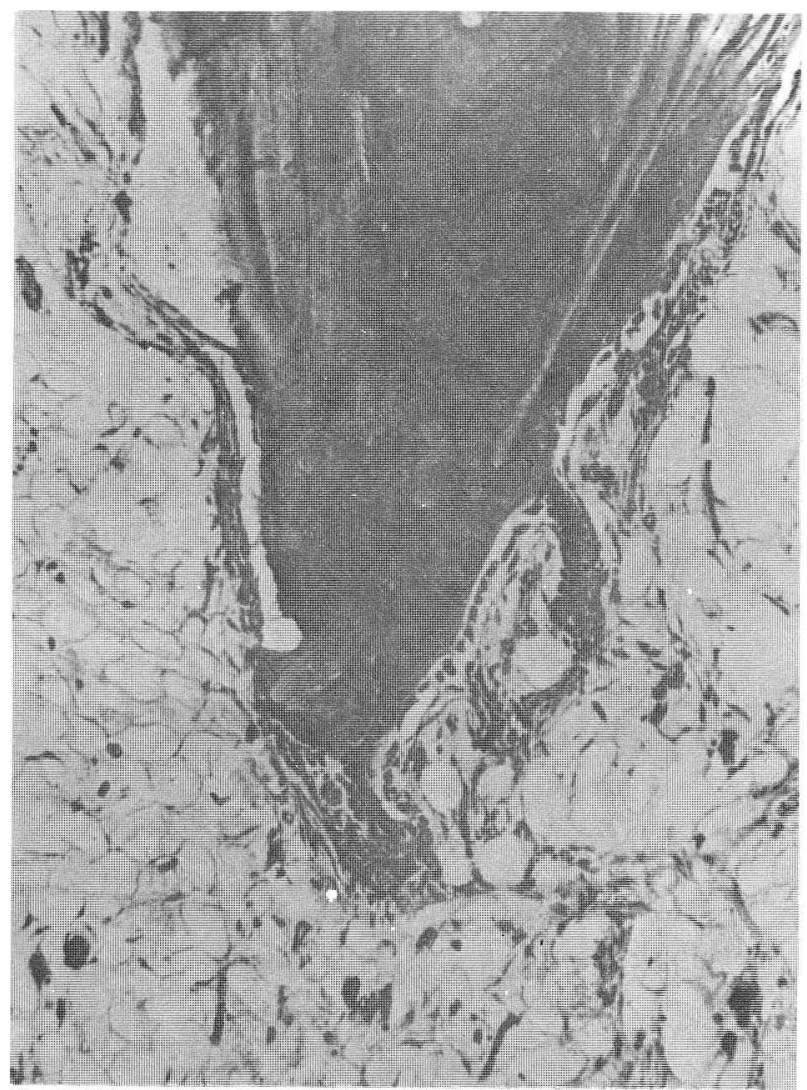

Fig. 4 Cão n! 12 Peça 23 Corte 1

- 7 dias pós-extração com curetagem 


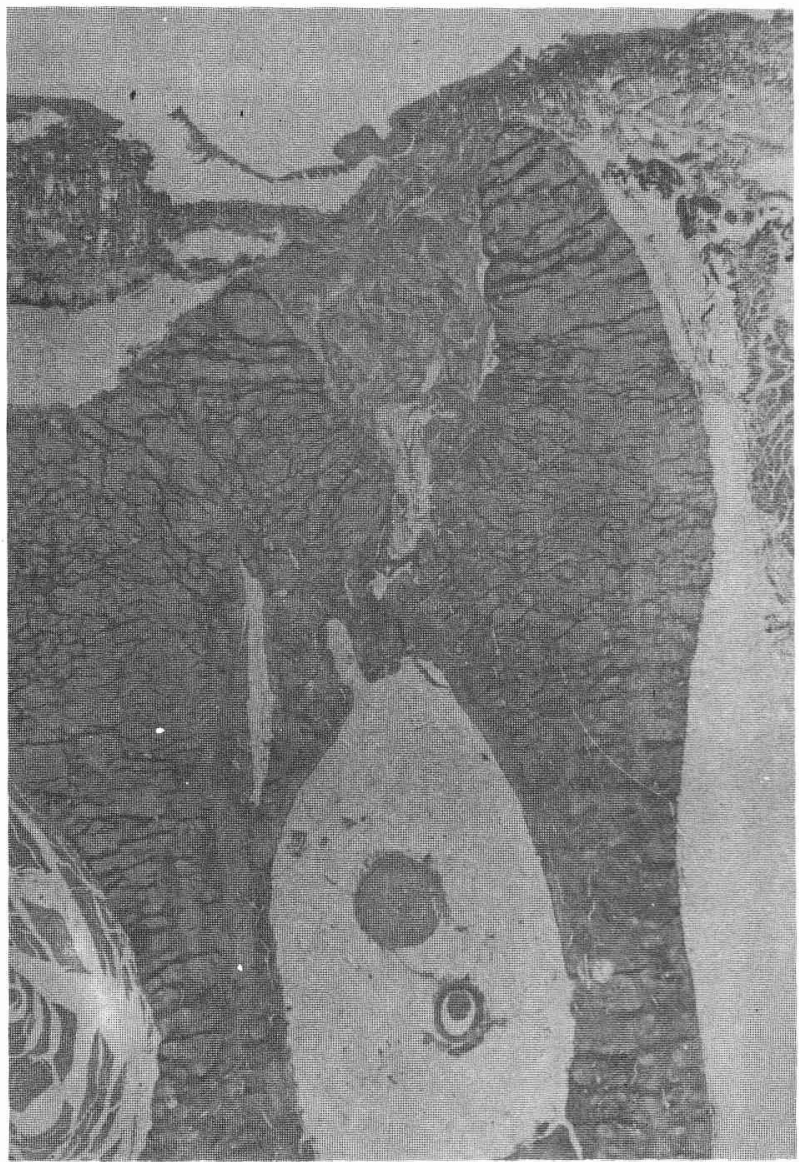

Fig. 5 Cão n! 17 Peça 33 Corte 9 21 dias pós-extração com curetagem 


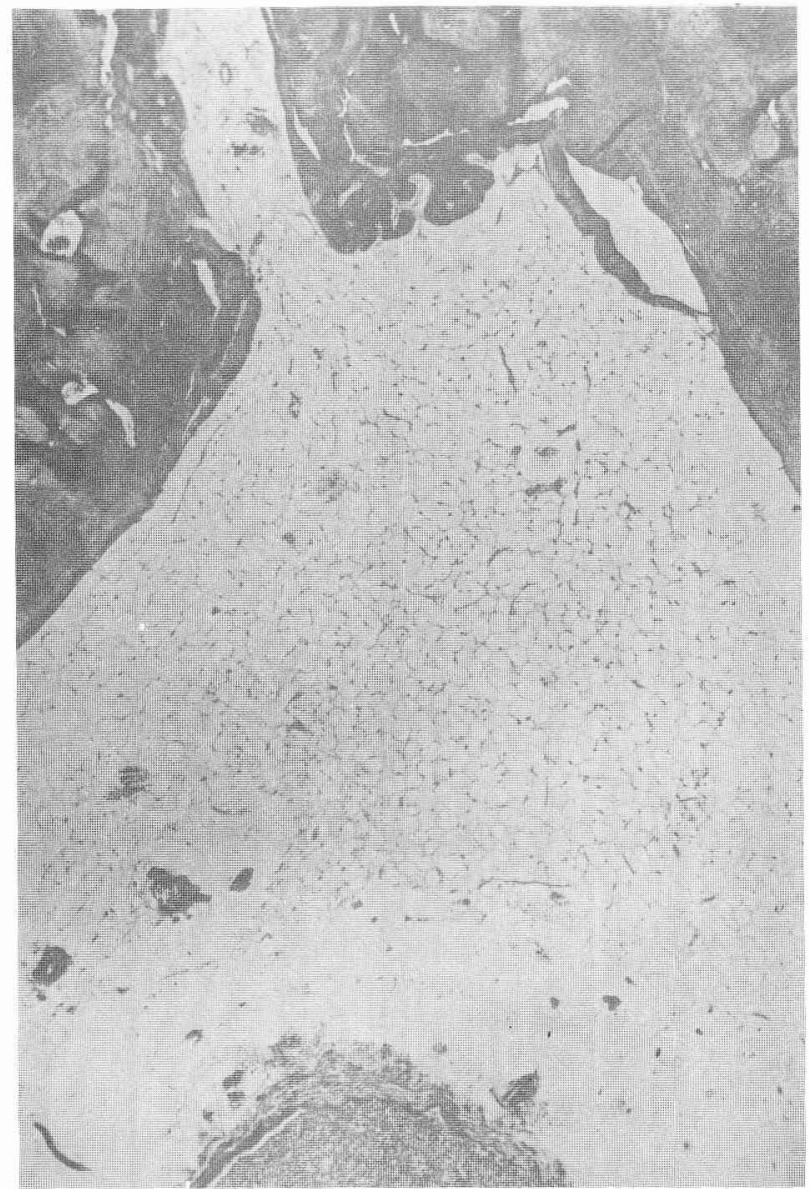

Fig. 6 Cão n? 17 Peça 33 Corte 9

21 dias pós-extração com curetagem 


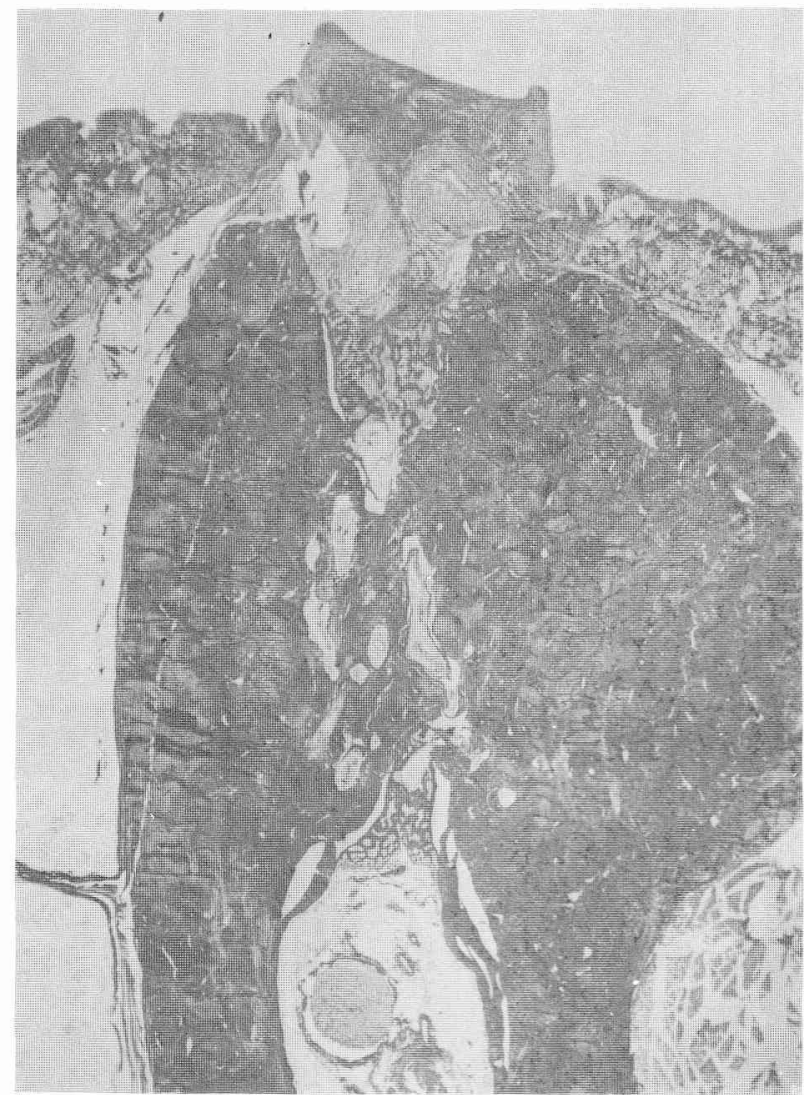

Fig. 7 Cão no 18 Peça 36 Corte 6 21 dias pós-extração sem curetagem 


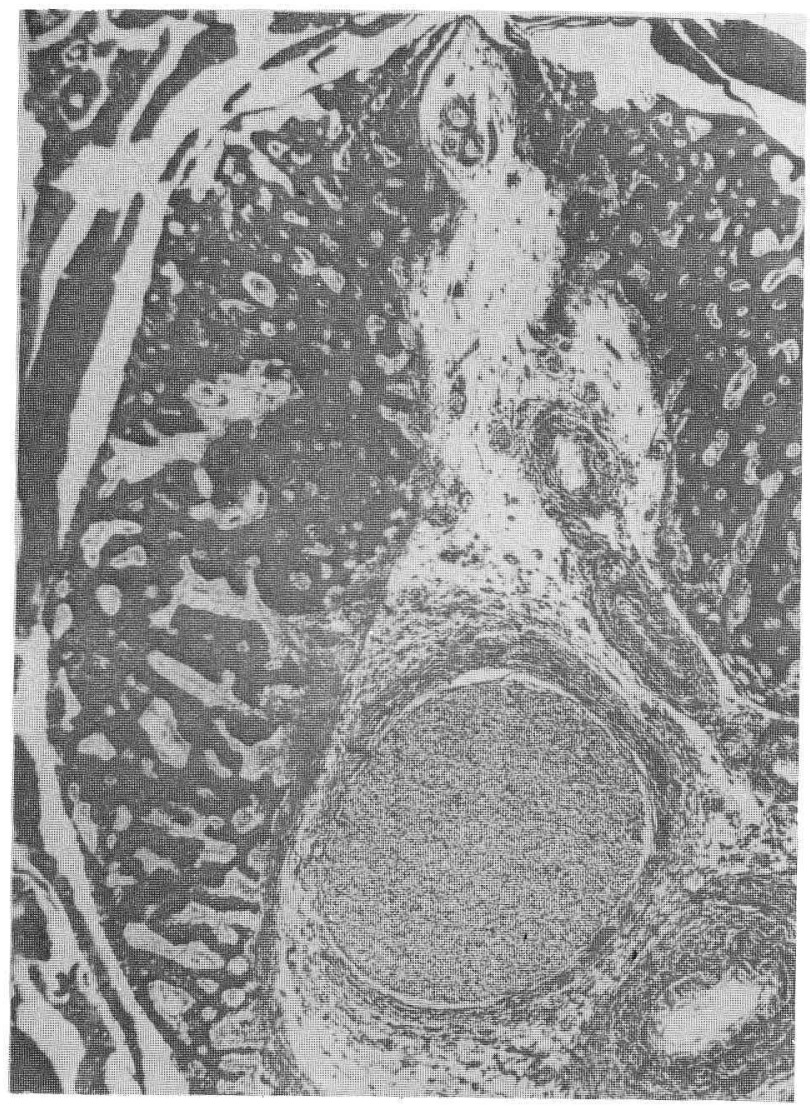

Fig. 8 Cão n? 20 Peça 39 Corte 18 28 dias pós-extração com curetagem 


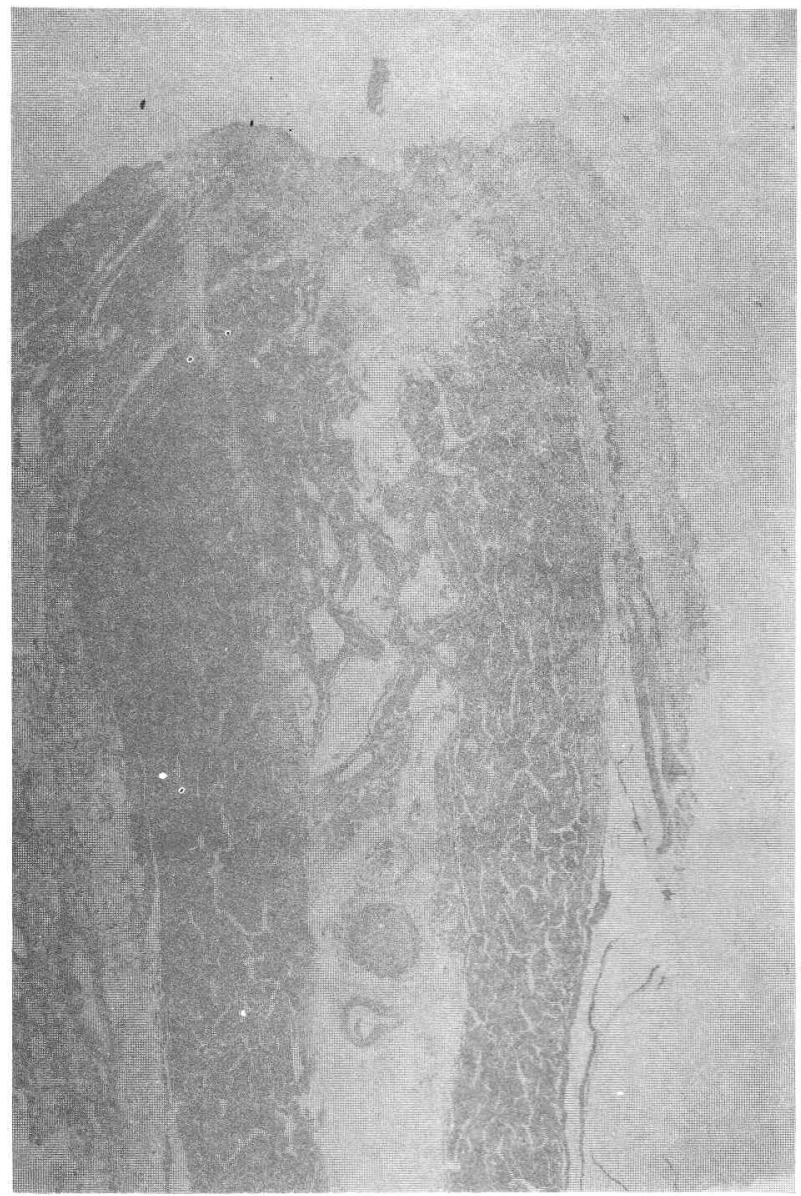

Fig. 9 Cão n! 23 Peça 45 Corte 30

28 dias pós-extração com curetagem

R. Fac. Odont. P.A. 


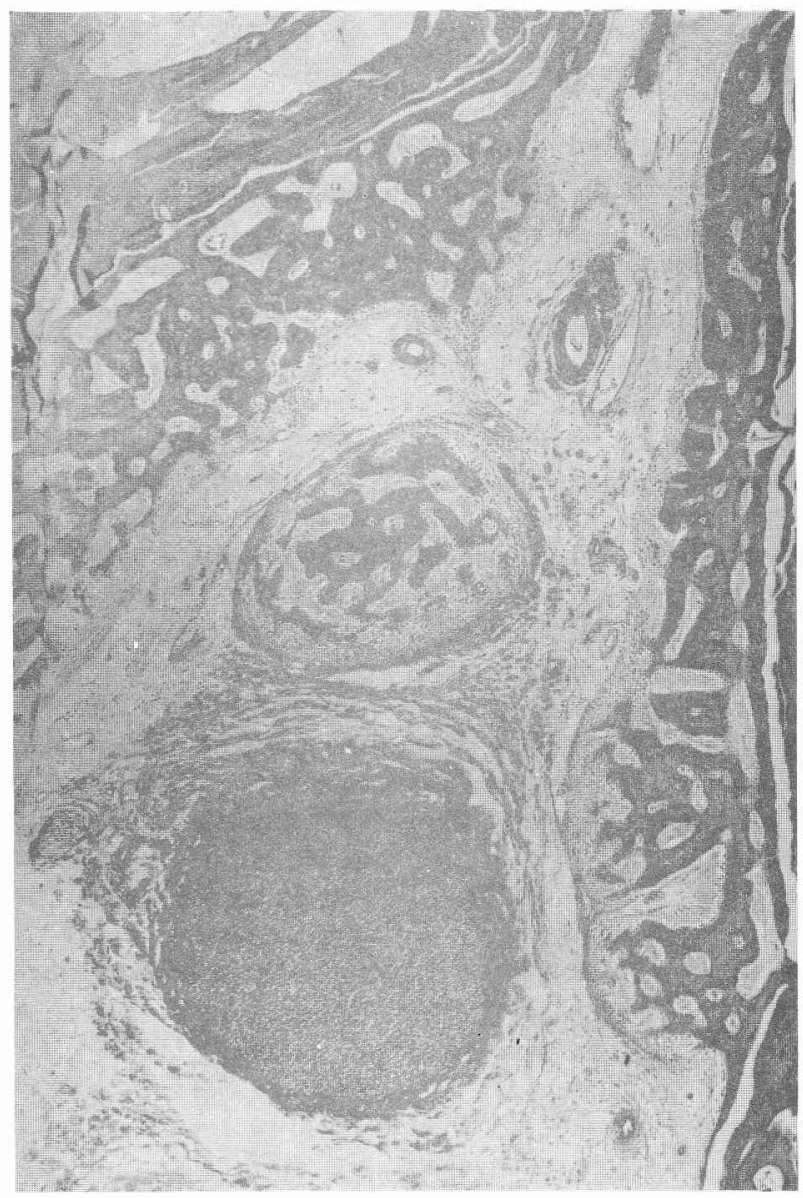

Fig. 10 Cão n? 23 Peça 45 Corte 30

- 28 dias pós-extração com curetagem 